\title{
Electric Train Energy Consumption Modeling
}

\author{
Jinghui Wang ${ }^{\mathrm{a}}$, Hesham A. Rakhab ${ }^{\mathrm{b}, *}$ \\ ${ }^{a}$ Center for Sustainable Mobility, Virginia Tech Transportation Institute,3500 Transportation Research \\ Drive, Blacksburg, VA 24061,USA \\ ${ }^{b}$ Center for Sustainable Mobility, Virginia Tech Transportation Institute,3500 Transportation Research \\ Drive, Blacksburg, VA 24061,USA
}

\begin{abstract}
The paper develops an electric train energy consumption modeling framework considering instantaneous regenerative braking efficiency in support of a rail simulation system. The model is calibrated with data from Portland, Oregon using an unconstrained non-linear optimization procedure, and validated using data from Chicago, Illinois by comparing model predictions against the National Transit Database (NTD) estimates. The results demonstrate that regenerative braking efficiency varies as an exponential function of the deceleration level, rather than an average constant as assumed in previous studies. The model predictions are demonstrated to be consistent with the NTD estimates, producing a predicted error of $1.87 \%$ and $-2.31 \%$. The paper demonstrates that energy recovery reduces the overall power consumption by $20 \%$ for the tested Chicago route. Furthermore, the paper demonstrates that the proposed modeling approach is able to capture energy consumption differences associated with train, route and operational parameters, and thus is applicable for project-level analysis. The model can be easily implemented in traffic simulation software, used in smartphone applications and eco-transit programs given its fast execution time and easy integration in complex frameworks.

Keywords: Electric train, Energy Consumption Model, Regenerative Braking Efficiency, Rail Transit Simulation
\end{abstract}

\section{Introduction}

The transportation sector has become the major consumer of energy and producer of greenhouse gas (GHG) emissions. Specifically, in 2014, transportation-related energy use accounted for $27 \%$ of the total world primary energy consumption and produced $34 \%$ of

\footnotetext{
${ }^{*}$ Corresponding Author.

Email address: hrakha@vt. edu (Hesham A. Rakha)
}

Preprint submitted to Journal of Applied Energy

February 1, 2017 
GHG emissions $\left(\mathrm{CO}_{2}\right)$ [1]. In the United States, the transportation sector is responsible for $28 \%$ of the total U.S. energy use and $34 \%$ of $\mathrm{CO}_{2}$ production [2,3]. The urban transportation system has been deteriorating with regards to the environment given the higher residential density and travel demand, growth in automobile ownership and worsening of traffic conditions. Many cities, especially metropolis areas, are served by a mixture of multiple traffic modes comprised of passenger cars, transit buses, trucks and rail transit. Accordingly, to reduce city-wide energy consumption and GHG emissions, not only are effective strategies required for each mode, but also integrated strategies considering the interaction of these modes are required. To enable the efficient and cost-effective design and testing of new strategies, a multi-modal simulation system is being developed in order to offer a simulated testbed applicable to multiple traffic modes.

Developing the proposed system requires the design of three modules: passenger car and transit vehicle modeling, subway system modeling, pedestrian and bicycle modeling. This paper focuses on subway system electric rail energy consumption modeling. The developed model will support the overall modeling framework by estimating rail-induced energy consumption and GHG emissions, and designing and testing eco-friendly strategies customized to urban rail transit systems, such as energy-efficient timetables [4, 5] and ecospeed control $[6,7]$.

\section{Literature review}

Energy consumption models can be divided into two categories: forward models and backward models. As demonstrated by [8], models that compute the tractive contribution required at the wheels and "work backward" towards the engine are called "backward models"; alternatively, models that start from the engine and work with transmitted and reflected torque are called "forward models". The use of forward models requires extensive internal engine data. These models are very complex and characterized by slow execution time and high computer memory. Backward models, however, achieve reliable evaluation of vehicle energy consumption based on drive cycle and vehicle characteristic data, without the need to input engine data. In addition, they are characterized by fast computational times and low memory usage, and can be easily implemented in complex frameworks such as simulation and intelligent transportation system (ITS) applications [9]. The backward modeling approach is thus used to develop the proposed modeling framework.

The effort on the review of the literature was made in terms of introducing the details of a subway system along with the system components relative to energy consumption modeling, and the existing backward modeling approaches on rail energy consumption. 


\subsection{Subway system components for energy modeling}

A subway, put simply, is a train and the tunnel through which the train runs. A subway train consists of several connecting cars that contain durable seats as well as poles and straps for people to hold on to when the train is full [10]. The trains, known as rolling stock, are complex given that they include a traction and dynamics system that highly impact energy consumption. For example, the traction system determines how the propulsive force is generated and provided to move a train forward; and the dynamics system determines how a train is accelerated or decelerated thus affecting train transient behavior that highly impacts instantaneous energy consumption. Also, the brake system determines whether the braking power is regenerated to be used or wasted as heat. For regenerative braking, the brake energy can be recovered by converting kinetic energy into a form that can be either immediately used or stored until needed; however, other brake systems, such as dynamic braking, dissipate electric energy as heat rather than using it. Other train characteristics, such as car empty weight, number of axles per rail car and drag coefficient significantly affect the forces acting on a train and thus are also important parameters in energy modeling.

In addition to the train itself, there are several other rail system components, such as track infrastructure and passenger loading, affecting the tractive/braking forces acting on the train. For instance, a good condition track (good rails and cross ties) decreases the starting tractive effort [11]; while a track with steep grades and large curvature results in high resistance forces $[11,12]$; and passenger loading affects the total railcar weight and thus acting forces. These factors should also be incorporated into the energy modeling framework.

\subsection{Existing rail energy modeling approaches}

The most widely available measures for rail (either electric or diesel-electric train) energy consumption are those estimated on an annual gross average basis. Specifically, Eq. (1)-(3) present the modeling approach, where $E_{p}, E_{s}$ and $E_{v}$ are the energy consumed per passenger kilometer $(k W h / P \cdot k m)$, per seating kilometer $(k W h / S \cdot k m)$ and per vehicle kilometer $(k W h / V \cdot k m)$, respectively; $E$ is the annual energy consumption of a rail transit system in $k W h ; M_{p}, M_{s}$ and $M_{v}$ are total passenger kilometers, seating kilometers and vehicle kilometers, respectively; $C$ is the train seating capacity and $\beta$ is the line loss factor associated with the train transmission system. The parameters in the models are readily available from the National Transit Database (NTD) [13-15]. Despite the effortless acquisition of the aggregated measurements, they are not capable of representing the differences in energy consumption associated with route and vehicle characteristics, passenger loading, speed profiles and weather and track conditions, and thereby not suitable 
for project-level analysis.

$$
\begin{aligned}
& E_{p}=\frac{E}{M_{p} \times \beta} \\
& E_{s}=\frac{E}{M_{s} \times C \times \beta} \\
& E_{v}=\frac{E}{M_{v} \times \beta}
\end{aligned}
$$

Research efforts have thus focused on developing a modeling framework sensitive to the aforementioned system characteristics. An early study conducted by Mittal [16] proposed an analytical method to estimate energy consumption sensitive to speed, train configuration and passenger load. However, the method used average speed for energy prediction without considering speed fluctuation. The model also did not incorporate an energy regeneration module. Some of the state-of-the-art models [17-22] considered an average constant regenerative braking energy efficiently that mainly depended on the train's average speed. The major limitation is that these models cannot capture vehicle transient behavior and model energy regeneration at a microscopic level. Although some of these simplified models have been used to develop energy-optimized strategies [23-28], the validity of the resulting strategies is questionable given the models' inadequacy in instantaneous energy prediction. The National Cooperative Rail Research Program (NCRRP) [29] designed a passenger rail simulation framework which incorporated route and train characteristics, speed, passenger load and regenerative braking into the energy modeling practice. The framework, however, is an excel-based tool and cannot be implemented in more complex frameworks, such as traffic simulation software, smartphone eco-driving and eco-routing systems. Furthermore, the energy prediction within the framework also considers average speed and a constant regenerative efficiency. A recent study [12] initiated a bottom-up modeling framework sensitive to acceleration behavior by incorporating second-by-second speed profiles. Nonetheless, the model cannot generate instantaneous energy regeneration because it assumes a constant regenerative efficiency. The model is also an excel-based tool and thus does not allow for integration in complex frameworks. Other models, such as [30-32], are also not suitable for ITS applications due to their complexity in model specification.

To the authors' best of knowledge, although there have been numerous studies on modeling rail electric consumption, these studies were of limited application especially for road 
electric vehicles ([33-37]). Specifically, they either cannot model train transient behavior or fail to capture energy regeneration at a microscopic level or are not simple enough to be implemented within complex systems (e.g. traffic simulation software and smartphone applications). The paper attempts to fill this void and, for the first time, relates energy regeneration with the instantaneous deceleration level in rail transit energy modeling.

\section{Modeling framework}

The proposed modeling framework characterizes the energy prediction as two piecewise functions, as demonstrated in Eq.(4) (energy consumption) and Eq.(5) (energy regeneration). The description of the model parameters is summarized in Table A1 in Appendix A. Basically, the energy is computed on a second-by-second basis. When the train is in traction mode, the energy flows from the electricity power system to the wheels with the power at the wheels being positive $(P>0)$. Alternatively, when the train is in regenerative braking mode, the energy flows from the wheels back to the power system and the power at the wheels is negative $(P<0)$. Noteworthy here is that, to compute regenerated energy $\left(E C_{r e}\right)$, only negative power is considered.

$\left(\alpha_{01} \times \beta_{1}+\alpha_{02} \times \beta_{2}\right)$ in Eq.(4) refers to the head-end power (HEP) in which $\beta_{1}$ and $\beta_{2}$ are dummy variables equal to either 0 or $1 . \alpha_{01}$, in most cases, is applied to HEP $\left(\beta_{1}=1\right.$ and $\beta_{2}=0$ ) except whan a train is about to start moving and waiting at the initial route station where only a small fraction of $\operatorname{HEP}\left(\alpha_{02}\right)$ is applied $\left(\beta_{1}=0\right.$ and $\left.\beta_{2}=1\right)$. This accounts for the fact that trains only keep the ventilation system and lights on while waiting to load passengers before a trip begins and thus only consumes a small fraction of HEP.

$$
\begin{aligned}
& E C(t)= \begin{cases}\alpha_{01} \times \beta_{1}+\alpha_{02} \times \beta_{2}+P(t), & \forall P(t)>0 \\
\alpha_{01} \times \beta_{1}+\alpha_{02} \times \beta_{2}, & \forall P(t) \leq 0\end{cases} \\
& E C_{r e}(t)= \begin{cases}P(t) \times \eta_{r b}(t), & \forall P(t)<0 \\
0, & \forall P(t) \geq 0\end{cases}
\end{aligned}
$$

The average energy consumption rate for an entire trip is then estimated by summing the instantaneous energy predictions and then dividing by the trip length, as illustrated in Eq. (6), with $d$ being the trip length $(\mathrm{km})$.

$$
E C_{d}[k W h / V \cdot k m]=\frac{\sum_{t}\left[E C(t)+E C_{r e}(t)\right]}{d}
$$




\subsection{Tractive power and tractive effort}

Tractive power is computed using Eq.(7) in which $u$ is the instantaneous speed $(\mathrm{km} / \mathrm{h})$, 0.746 is used to convert the power from horsepower to kilowatt. $F$ is the tractive effort as formulated in Eq.(8) [11]. The first four terms, $\left(0.6+\frac{20}{w_{p}}+\frac{0.01 u(t)}{1.61}+\frac{K(u(t) / 1.61)^{2}}{w_{p} n_{p}}\right)$, in the model are the modified Davis equation [38], referring to the train resistance comprised of rolling, journal, track, flange and aerodynamic resistance. $w_{p}$ is the railcar weight per axle (ton), including passenger weight (an average of $68 \mathrm{~kg}$ is assumed for each passenger in this study). The Davis equation was tested through a large amount of field experiments [38-40]. In addition, as demonstrated by [11, 12, 41], only positive gradient contributes to the grade resistance with an increase of $20 \mathrm{lbs} /$ ton $(0.01 \mathrm{~N} / \mathrm{kg})$ per percentage grade. It should be noted that curve resistance has been converted to the equivalent grade resistance by assuming that unit resistance of a $1^{\circ}$ curve is the same as the resistance that a $0.04 \%$ grade would offer [11]. The last term in the bracket is the force exerted for acceleration or braking. $M$ is the average weight of the moving train (ton), including the train curb weight and total passenger weight. 4.4482 is used to convert the tractive effort from lbs to $N$.

$$
\begin{aligned}
& P=\frac{F u}{375 \times 1.61} \times 0.746 \\
& F(t)=\left[\left(0.6+\frac{20}{w_{p}}+\frac{0.01 u(t)}{1.61}+\frac{K(u(t) / 1.61)^{2}}{w_{p} n_{p}}+20 \theta\right)\right. \\
& \left.+70 \frac{u(t)^{2}-u(t-1)^{2}}{8.4 \times L}\right] \times M \times 4.4482
\end{aligned}
$$

\subsection{Starting tractive effort}

It is worth noting that the tractive force in Eq.(8) only addresses the effort exerted to move the train while in motion. However, a different tractive force is needed to move a train from a complete stop. The starting tractive effort typically consists of the grade resistance, bearing resistance, track resistance, weather resistance, and the resistance resulting from poor track conditions. When a train is starting from a complete stop, the tractive effort is estimated as the sum of these resistance forces rather than using Eq. (8).

The grade resistance can be estimated as set forth. The typical values of other resistance forces were suggested by [12]. Specifically, the bearing resistance is $10 \mathrm{lb} / \mathrm{ton}$ $(0.005 \mathrm{~N} / \mathrm{kg})$ at $122{ }^{\circ} \mathrm{C}\left(50^{\circ} \mathrm{F}\right)$, and increases by $0.1 \mathrm{lb} / \operatorname{ton}(0.0005 \mathrm{~N} / \mathrm{kg})$ for $1{ }^{\circ} \mathrm{F}$ decrease below $50{ }^{\circ} \mathrm{F}$ and decreases by $0.1 \mathrm{lb} / \operatorname{ton}(0.00005 \mathrm{~N} / \mathrm{kg})$ for $1{ }^{\circ} \mathrm{F}$ increase above $50{ }^{\circ} \mathrm{F}$. Track resistance depends on track type. There is no resistance force for $130 l b$ (59 
$\mathrm{kg})$ rail, and $1 \mathrm{lb} / \operatorname{ton}(0.0005 \mathrm{~N} / \mathrm{kg})$ resistance for $115 \mathrm{lb}(52 \mathrm{~kg})$ rail and $2 \mathrm{lb} /$ ton $(0.001$ $\mathrm{N} / \mathrm{kg}$ ) for $100 \mathrm{lb}(45 \mathrm{~kg})$ rail. Weather resistance is affected by the humidity of the rail. Basically, there is no weather resistance for dry rail, while the wet rail produces a $2 \mathrm{lb} / \mathrm{ton}$ $(0.001 \mathrm{~N} / \mathrm{kg})$ resistance. The resistance of icy or snowy rail goes up to $10 \mathrm{lb} /$ ton $(0.005$ $\mathrm{N} / \mathrm{kg}$ ). The resistance relative to track conditions is $2 \mathrm{lb} / \operatorname{ton}(0.001 \mathrm{~N} / \mathrm{kg})$ for poor rails and fair cross ties, and $7 \mathrm{lb} / \mathrm{ton}(0.0035 \mathrm{~N} / \mathrm{kg})$ for poor rails and poor cross ties. There is no such resistance if both rails and cross ties are in good condition.

\subsection{Regenerative braking efficiency}

Regenerative braking efficiency accounts for the portion of the total braking energy available for recovering. It determines the amount of the energy recovered by a regenerative braking system. The trains operating on an urban rail transit system frequently accelerate and decelerate given the short distance between two stations, so that a large amount of energy may potentially be recovered. Failing to account for energy recovery may thus result in large deviation in energy prediction for trains with regenerative braking.

The regenerative efficiency $\left(\eta_{r e}\right)$ was characterized as an exponential function of the deceleration level for electric vehicles [8, 42], as formulated in Eq.(9). The model demonstrates that higher deceleration levels result in larger regenerative efficiency and thus more energy recovery. This functional form was thus used in the proposed model to compute the train regenerative energy. The calibration of the model parameter $(\alpha)$ is presented in Section 4.

$$
\eta_{r e}(t)= \begin{cases}\frac{1}{e^{\frac{\alpha}{|a(t)|}}}, & \forall a(t)<0 \\ 0, & \forall a(t) \geq 0\end{cases}
$$

\section{Model calibration}

Having introduced the modeling framework, the next step is to calibrate the proposed model, which requires only one parameter to be calibrated.

The data required for calibration were classified into four categories: train information, travel activity data, route characteristics, and the information required to estimate the starting tractive effort. The data were provided by researchers at Georgia Tech who requested the data from the Tri-County Metropolitan Transportation District of Oregon (TriMet), the public agency that operates mass transit in the Portland Metropolitan area. TriMet responded with the information for the Metropolitan Area Express (MAX) Blue Line.

The MAX light rail trains are powered by built-in-place electric substations (ESS) located along the system route using the overhead contact line ([43]) with a nominal Voltage 


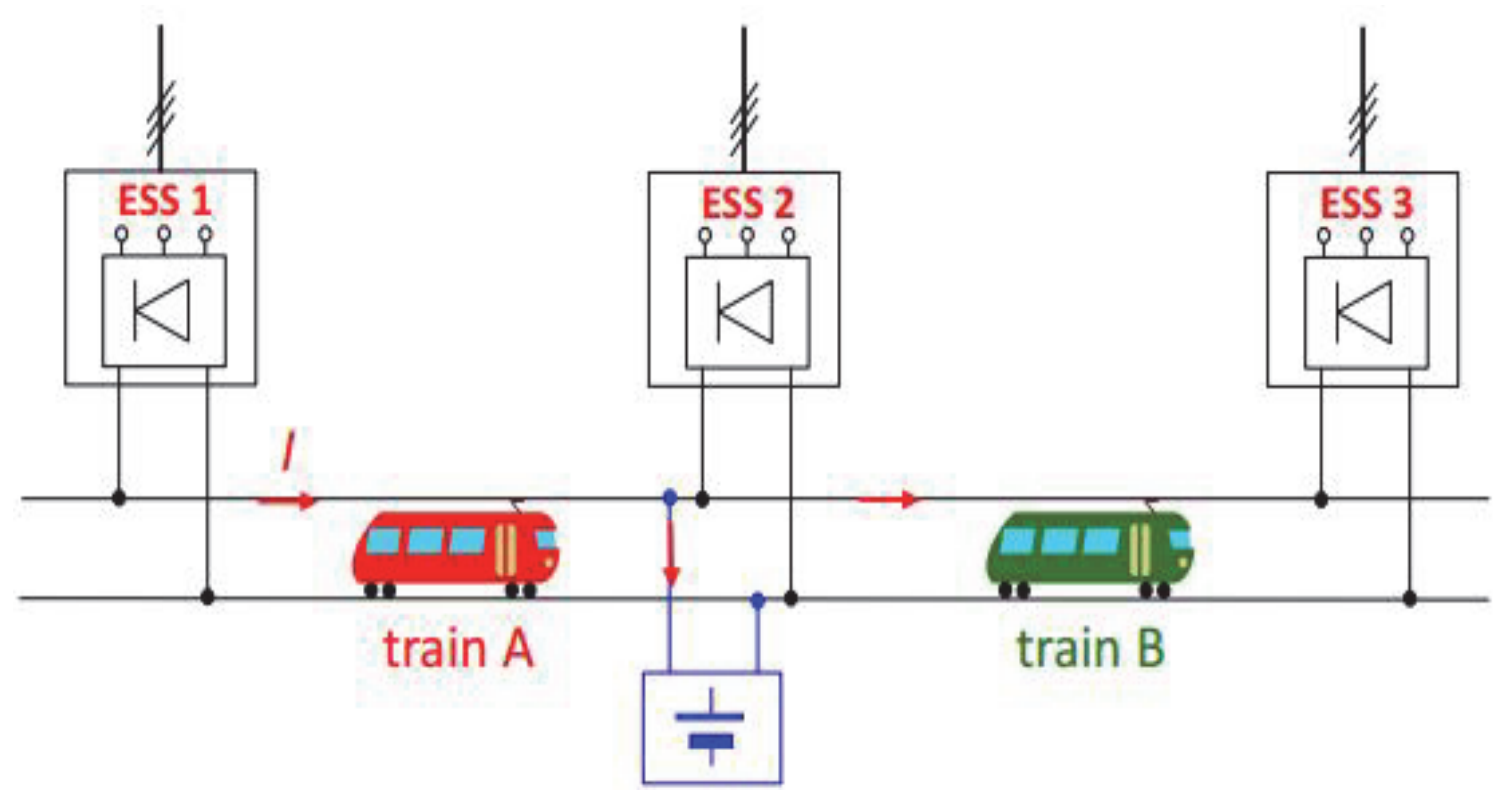

Fig. 1: A simplified representation of the MAX light rail traction system (Source: [44])

of $825 \mathrm{VDC}$. The system under study is similar to that investigated by [44, 45]. As illustrated in Fig. 1, the electric power is transferred from ESS to trains through the contact line. The brake system of the MAX trains is a blending of regenerative braking and friction braking. The regenerative braking is the primary method of braking used when the train is going faster than $3 \mathrm{mph}(4.8 \mathrm{~km} / \mathrm{h})$, and the friction braking is also applied when the speed of the train is slower than $4,8 \mathrm{~km} / \mathrm{h}$ to ensure sufficient power supply for emergency stopping. In addition, when the train is in braking mode, the electric motors operate like generators, taking the forward motion of the train and converting it into electricity. The regenerated electricity is then partly sent to other trains and partly stored in lineside storage systems for later usage, which significantly improves the system power efficiency. For example, as demonstrated by Fig. 1, the braking power from train A is partly sent to train B and partly stored in the storage system around ESS 2.

A typical train model (SD 660), as shown in Fig. 2, manufactured by Siemens, was tested in the field by TriMet to construct the calibration dataset. The test vehicle had two connecting cars each of which provided with 64 seats. The specific information of the testing rolling stock is illustrated in Table 1, including the empty railcar weight, number of axles per rail car, drag coefficient, seating capacity, passenger loading, number of cars per train, and HEP. The HEP was simplified to three operational levels: normal, high and maximum. The normal level operates at one-third of the maximum load $(25 \mathrm{~kW})$, and the 


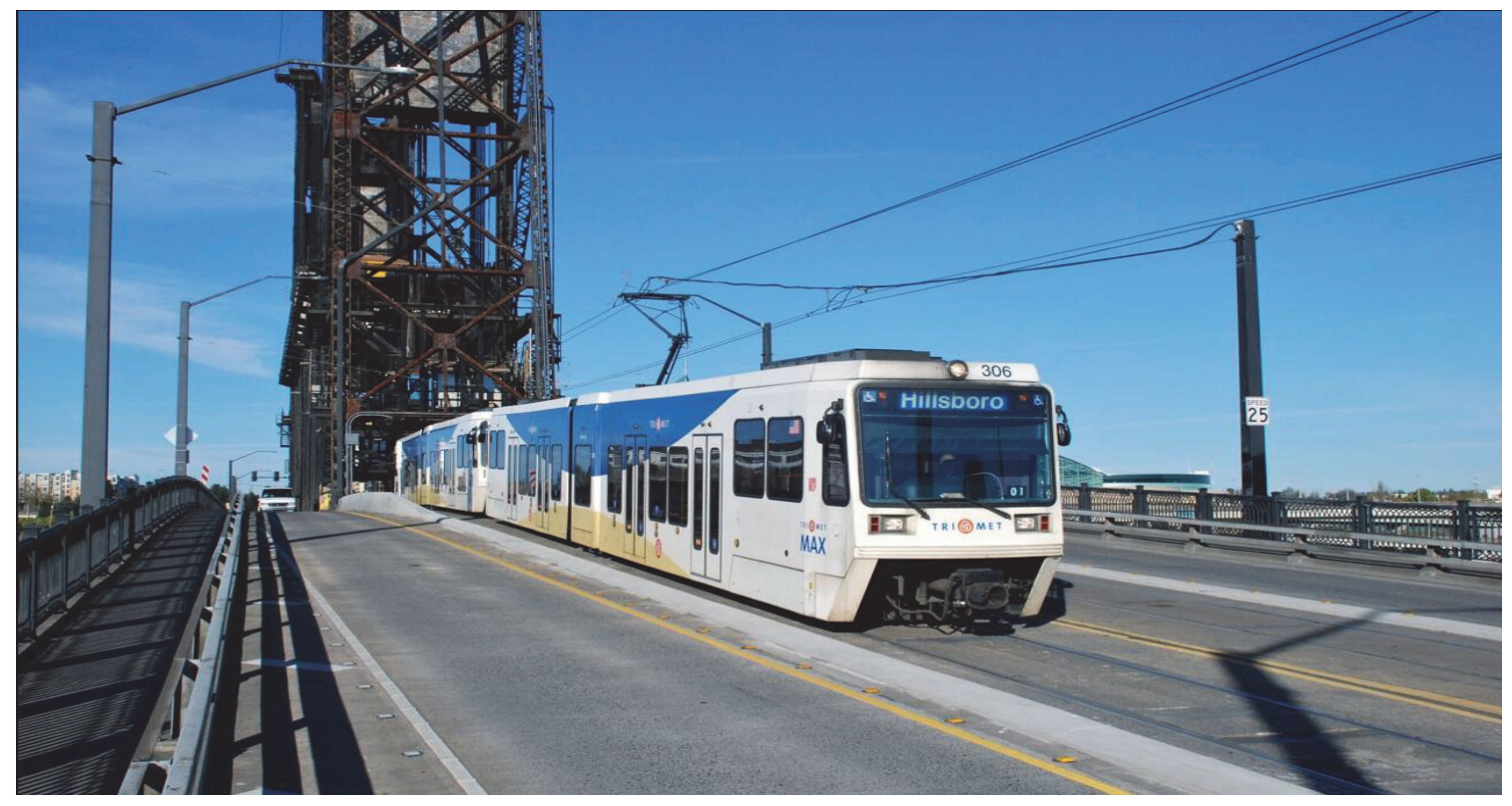

Fig. 2: Portland MAX light rail vehicle

high level functions at two-thirds followed by the maximum level that operates at full load. It should be noted that the Chicago train in the table was used for validation purposes.

The characteristics of the testing route are provided in Table B1 of Appendix B in terms of station name, milepost, elevation and gradient profiles (the curvature has been converted to its equivalent grade as mentioned in section 3.1). The trip starts from the Hatfield Government Center Station and ends at Cleveland station, covering an entire trip of the line with a total distance of 32.4 miles $(52.16 \mathrm{~km})$. The vertical layout of the section demonstrates a combination of upgrade (up to $4.26 \%$ ) and downgrade (up to $4.46 \%$ ) sections.

The information required to estimate the starting tractive effort, as illustrated in Table 2, consists of weather condition, ambient temperature, track type and conditions. The test runnings in Portland and Chicago were both conducted on 115-lb good rails with good cross ties at normal temperature on sunny days. The test in Portland delivered the MAX Blue Line driving cycle with a maximum operational speed of $88 \mathrm{~km} / \mathrm{h}$ and a total duration of around $6000 \mathrm{~s}$, as illustrated in Fig. 3. For each between-station running, the train, in general, was first accelerated from a complete stop at one station to a specified target speed, then cruised at the target speed for a spell, and decelerated until achieving a complete stop at the next station.

The exponential feature of the regenerative efficiency in Eq. (9) results in a non- 
Table 1: Test train characteristics

\begin{tabular}{lll}
\hline & \multicolumn{2}{c}{ Values } \\
\cline { 2 - 3 } Parameter & MAX blue & Chicago Brown \\
\hline Weight of empty car (ton) & 54.5 & 27.15 \\
Number of axles per car & 6 & 4 \\
Drag coefficient & 0.07 & 0.07 \\
Seating capacity per car & 64 & 49 \\
Percentage loading (peak period) & na & $87.5 \%$ \\
Percentage loading (off-peak period) & na & $25 \%$ \\
Daily percentage loading & $43 \%$ & $45 \%$ \\
Number of cars per train (peak period) & 2 & 6 \\
Number of cars per train (off-peak period) & 2 & 4 \\
Maximum HEP per car $(k W$ ) & 25 & 25 \\
HEP operating level & Normal & Normal \\
\hline
\end{tabular}

Table 2: Parameter set for starting tractive effort

\begin{tabular}{lll}
\hline & \multicolumn{2}{c}{ Values } \\
\cline { 2 - 3 } Parameter & MAX Blue & Chicago Brown \\
\hline Ambient temperature $\left({ }^{\circ} \mathrm{F}\right)$ & 74 & 74 \\
Weather condition & Dry & Dry \\
Track type & $115 \mathrm{lb}(52 \mathrm{~kg})$ rail & $115 \mathrm{lb}(52 \mathrm{~kg})$ rail \\
Track condition & Good rails and crossties & Good rails and crossties \\
\hline
\end{tabular}




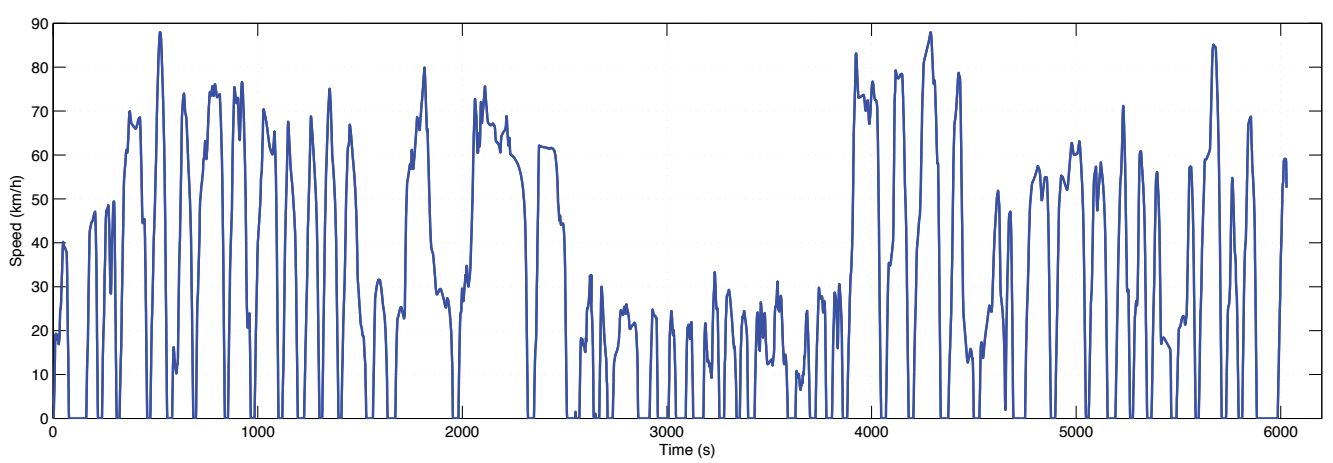

Fig. 3: The driving cycle for the MAX Blue Line

linear energy consumption model, and thus the calibration procedure was formulated as an unconstrained non-linear optimization problem as shown in Eq. (10), where $D$ is the model prediction difference relative to the NTD estimates, and $E C_{N T D}$ is the NTD average energy rate. The NTD energy rate was used to calibrate the model because the field energy consumption was unavailable at the moment of model development. The data in the NTD 2011 demonstrated an average energy consumption of $13.57 \mathrm{kWh} / \mathrm{V} \cdot \mathrm{mi}(8.48 \mathrm{kWh} / \mathrm{V}$. $\mathrm{km})$. The model was calibrated by varying the model parameter $(\alpha)$ value to achieve the minimum prediction error.

$$
\min \quad D=\left(E C_{d}-E C_{N T D}\right)^{2}
$$

The calibration result generates the optimum model parameter of 0.65 ( $\alpha=0.65$ ). The resulting regenerative efficiency, as demonstrated in Fig. 4, exponentially decays with a decrease in the deceleration level. In particular, the decay becomes dramatic when the deceleration level is less than $2 \mathrm{~m} / \mathrm{s}^{2}$.

\section{Model validation}

The model was validated using the data from the Chicago heavy rail system. The validation effort was first made by comparing model predictions against the NTD 2011 estimates, followed by a further discussion of modeling results. The NTD energy consumption for the Chicago rail system was $36.44 \mathrm{kWh} / V M(22.63 \mathrm{kWh} / \mathrm{V} \cdot \mathrm{km})$ and $0.13 \mathrm{kWh} / \mathrm{SM}(0.08 \mathrm{kWh} / \mathrm{S} \cdot \mathrm{km})$.

\subsection{Energy consumption}

A train on the Chicago "L" system was tested by Georgia Tech researchers to collect the trajectory data for energy prediction. The Chicago rail has the similar traction and 


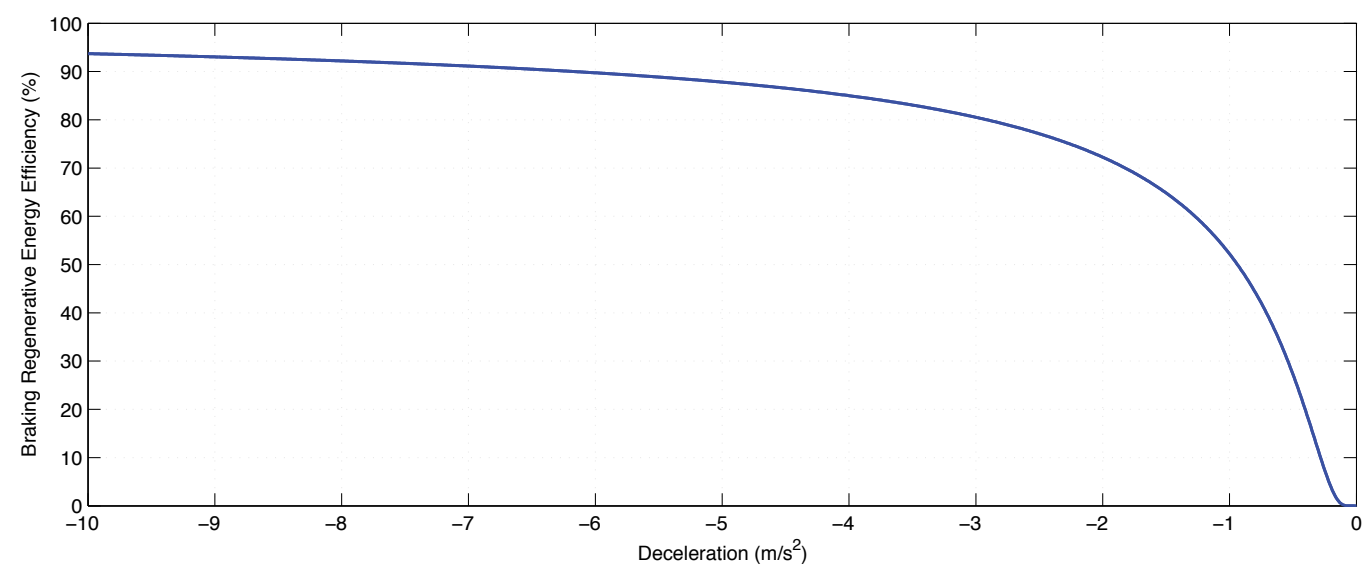

Fig. 4: Regenerative braking efficiency varies as a function of the deceleration level

brake system, track infrastructure and vehicle aerodynamics compared to the Portland rail system. The information for the testing vehicle is illustrated in Table 1. Compared to the train running on the MAX Blue Line, the Chicago train has lower empty car weight, seating capacity and the number of axles while more connecting cars. The testing route, as demonstrated in Table B2, starts from the Kimball station and ends at the Merchandise Mart station, covering $8.7 \mathrm{mi}(14.01 \mathrm{~km})$ section of the Chicago Brown Line. The vertical layout of the section demonstrates a combination of upgrade (up to 2.37\%) and downgrade (up to $-2.55 \%$ ). The test was completed under the same weather and rail conditions as those on the MAX Blue Line in order to ensure the identical bearing, track and weather resistance between calibration and validation processes. The test results in the Chicago Brown Line driving cycle with a maximum operational speed of $75 \mathrm{~km} / \mathrm{h}$ and a total duration of around $2000 s$, as illustrated in Fig. 5. It is worth noting that the number of cars and passenger load differ between the peak and the off-peak periods, resulting in different train weights at different periods. Consequently, energy consumption was first estimated for each period respectively, and then the average of the two periods was compared against the NTD data.

Table 3 demonstrates that the model predictions are consistent with the NTD estimates, generating a predicted error of $1.87 \%(\mathrm{kWh} / \mathrm{V} \cdot \mathrm{mi})$ and $-2.31 \%(\mathrm{kWh} / \mathrm{S} \cdot \mathrm{mi})$. Not modeling regenerative braking ("No regeneration" as shown in Table 3) results in a significant prediction error (27.39\% and $21.54 \%$ ). Modeling the regenerative efficiency as a constant also produces much higher prediction errors compared to the proposed model $(16.11 \%$ and $10.77 \%$ ). Furthermore, the constant assumption deems the model incapable of capturing instantaneous energy regeneration so it is not suitable for a microscopic level analysis. 


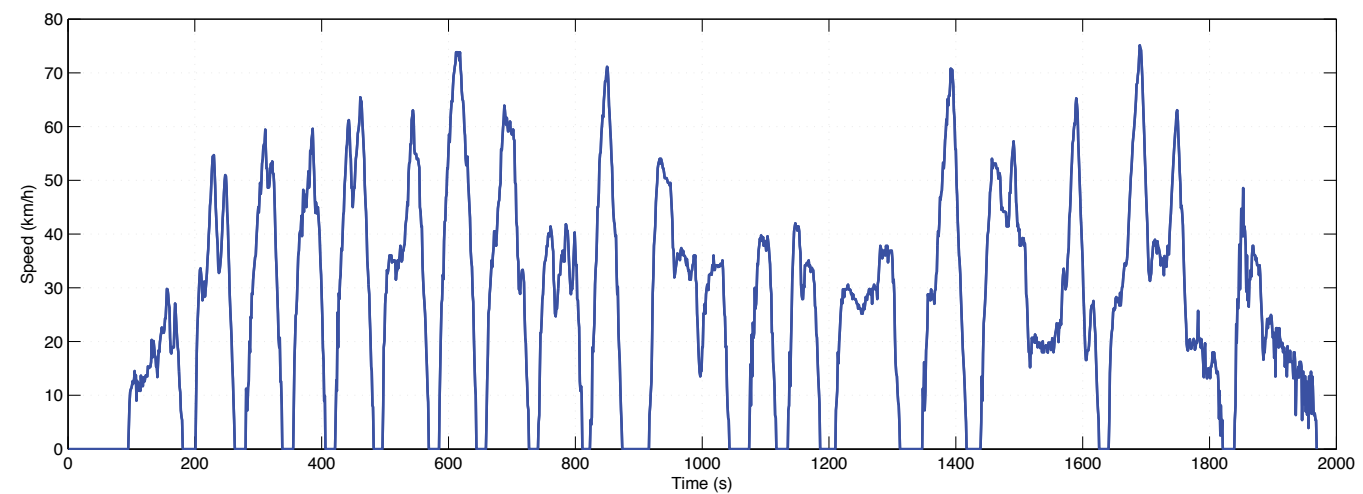

Fig. 5: The driving cycle for the Chicago Brown line

Table 3: Validation on Energy Prediction

\begin{tabular}{|c|c|c|c|c|c|c|c|}
\hline & \multirow{2}{*}{$\begin{array}{l}\text { NTD } \\
\text { esti- } \\
\text { mates }\end{array}$} & \multicolumn{2}{|c|}{ Instantaneous regeneration } & \multicolumn{2}{|c|}{ Constant regeneration } & \multicolumn{2}{|c|}{ No regeneration } \\
\hline & & $\begin{array}{l}\text { Predicted } \\
\text { energy }\end{array}$ & Error & $\begin{array}{l}\text { Predicted } \\
\text { energy }\end{array}$ & Error & $\begin{array}{l}\text { Predicted } \\
\text { energy }\end{array}$ & Error \\
\hline $\begin{array}{l}k W h / V . \\
m i\end{array}$ & 36.44 & 37.12 & $1.87 \%$ & 42.31 & $16.11 \%$ & 46.42 & $27.39 \%$ \\
\hline $\begin{array}{l}k W h / V \cdot \\
k m\end{array}$ & 22.63 & 23.06 & & 26.28 & & 28.83 & \\
\hline $\begin{array}{l}k W h / S . \\
m i\end{array}$ & 0.13 & 0.127 & $-2.31 \%$ & 0.144 & $10.77 \%$ & 0.158 & $21.54 \%$ \\
\hline $\begin{array}{l}k W h / S . \\
k m\end{array}$ & 0.08 & 0.079 & & 0.089 & & 0.098 & \\
\hline
\end{tabular}



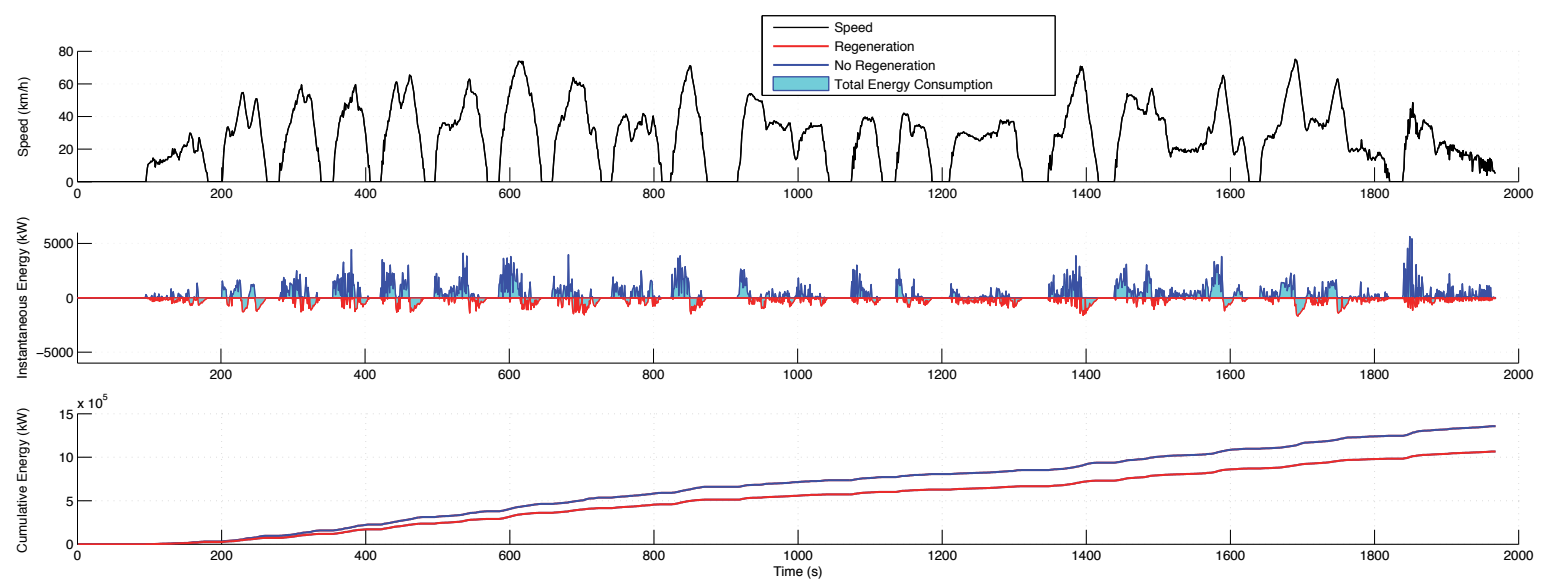

Fig. 6: Chicago Brown Line: speed and electric power on the entire cycle

Fig. 6 demonstrates the adequacy of the model at an instantaneous level. The light blue area represents the energy consumed for the entire cycle. The area delimited by the blue edge line refers to the energy consumption without energy regeneration during braking, and the red edge line represents the case considering energy regeneration. When the train is in traction mode, the electric power is positive and the energy flows from the overhead catenary to the wheels; alternatively, when the train is in brake mode, the power is negative and the energy is sent back to the overhead catenary. The instantaneous variation in the cumulative energy consumption demonstrates the ability of the model in adequately predict electric consumption and energy recovery on an instantaneous basis. Fig. 6 also reveals that energy recovery significantly reduces the overall power consumption.

\subsection{Discussion of modeling results}

The model predictions in Table 3 also demonstrate that regenerative braking achieves an energy saving of $20 \%$ by reducing the energy consumption from $46.42 \mathrm{kWh} / \mathrm{V} \cdot \mathrm{mi}$ $(28.83 \mathrm{kWh} / \mathrm{V} \cdot \mathrm{km})$ to $37.12 \mathrm{kWh} / \mathrm{V} \cdot \mathrm{mi}(23.06 \mathrm{kWh} / \mathrm{V} \cdot \mathrm{km})$. This predicted energy saving is consistent with what is reported in the literature [46-48], which demonstrated an energy saving of up to $30 \%$.

Furthermore, the proposed modeling approach is able to account for the impact of train parameters (number of cars, seating capacity) on energy consumption. A comparative analysis of predicted energy consumption between the MAX Blue Line and the Chicago Brown Line demonstrates that the Chicago train consumes approximately $174 \%$ more energy in $k W h / V \cdot m i$ (13.57 vs. 37.12), while only consumes $20 \%$ more for per seating mile $(0.106$ vs. 0.127$)$. This demonstrates that the Chicago train has significantly more 
Table 4: Sensitivity of model predictions to railcar empty weight

\begin{tabular}{llllll}
\hline \multirow{2}{*}{$\begin{array}{l}\text { Car weight } \\
\text { increment }\end{array}$} & Empty car & \multicolumn{3}{l}{ Predicted energy consumption } & Energy consumption increment \\
\cline { 3 - 6 }$($ ton $)$ & weight & $k W h / V \cdot$ & $k W h / V$ & $k W h / V \cdot$ & $k W h / V \cdot$ \\
& $($ ton $)$ & $m i$ & $k m$ & $m i$ & $k m$ \\
\hline-10 & 17.15 & 25.92 & 16.10 & -11.20 & -6.96 \\
-5 & 22.15 & 31.52 & 19.58 & -5.60 & -3.48 \\
0 & 27.15 & 37.12 & 23.06 & 0.00 & 0.00 \\
5 & 32.15 & 42.72 & 26.53 & 5.60 & 3.48 \\
10 & 37.15 & 48.32 & 30.01 & 11.20 & 6.96 \\
\hline
\end{tabular}

per-train seats. The Chicago train has lower car seating capacity (49 as shown in Table 1) yet more connecting cars, resulting in higher per-train seating.

In addition, the sensitivity of the model predictions to train weight and road grade was analyzed. It should be noted that the energy consumption increments in Table 4 and Table 5 are relative to the base case in which the empty car weight is 27.15 tons and the number of cars is 6 for the peak period and 4 for the off-peak period; and the increments in Table 6 are relative to the case with level grade. As illustrated in Table 4, the original empty car weight (27.15 tons) was either decreased or increased by 5 and 10 tons, respectively, generating an identical energy consumption increase of $5.6 \mathrm{kWh} / \mathrm{V} \cdot \mathrm{mi}(3.48 \mathrm{kWh} / \mathrm{V} \cdot \mathrm{km})$ for every 5 ton increment. For the original car weight, the number of cars for the base case was either decreased or increased by 1 at a time. The increasing number of cars results in an identical electric consumption increment of $6.19 \mathrm{kWh} / \mathrm{V} \cdot \mathrm{mi}(3.84 \mathrm{kWh} / \mathrm{V} \cdot \mathrm{km})$, as demonstrated in Table 5. Either increasing car weight or adding more connecting cars leads to linear and identical growth of energy consumption. However, increasing the road grade, from $0 \%$ to $4 \%$ as illustrated in Table 6 , produces a non-linear feature by having higher energy consumption increments on steeper roads. For example, the energy consumption increases by $9.2 \%$ (from 27.11 to $29.61 \mathrm{kWh} / \mathrm{V} \cdot \mathrm{km}$ ) with the grade varying from $3 \%$ to $4 \%$, while increases by only $5.3 \%$ (from 22.25 to $23.44 \mathrm{kWh} / \mathrm{V} \cdot \mathrm{km}$ ) with the grade varying from $0 \%$ to $1 \%$. This implies that, on steeper roads, the identical gradient increase results in larger energy consumption increases. The sensitivity analysis demonstrates the model's ability to capture energy consumption differences associated with vehicle weight and route characteristics.

Finally, the MAX Blue Line driving cycle was applied to the Chicago train, generating an average energy consumption of $23.10 \mathrm{kWh} / \mathrm{V} \cdot \mathrm{mi}(14.35 \mathrm{kWh} / \mathrm{V} \cdot \mathrm{km})$, which is significantly lower than that for the Chicago Brown Line cycle $(37.12 \mathrm{kWh} / \mathrm{V} \cdot \mathrm{mi})$. A further analysis, as illustrated in Fig. 7, demonstrates that the higher electric consumption for the 
Table 5: Sensitivity of model predictions to the number of railcars

\begin{tabular}{lllllll}
\hline & \multicolumn{2}{c}{ Number of cars } & \multicolumn{2}{l}{ Predicted energy consumption } & \multicolumn{2}{l}{ Energy consumption increment } \\
\cline { 2 - 7 } $\begin{array}{l}\text { Number of cars } \\
\text { increment }\end{array}$ & Peak & $\begin{array}{l}\text { Off- } \\
\text { peak }\end{array}$ & $\begin{array}{l}k W h / V \\
m i\end{array}$ & $\begin{array}{l}k W h / V \\
k m\end{array}$ & $\begin{array}{l}k W h / V \\
m i\end{array}$ & $k W h / V$ \\
\hline-2 & 4 & 2 & 24.74 & 15.37 & -12.38 & $k m$ \\
-1 & 5 & 3 & 30.93 & 19.21 & -6.19 & -3.68 \\
0 & 6 & 4 & 37.12 & 23.06 & 0.00 & 0.00 \\
1 & 7 & 5 & 43.31 & 26.90 & 6.19 & 3.84 \\
2 & 8 & 6 & 49.50 & 30.75 & 12.38 & 7.68 \\
\hline
\end{tabular}

Table 6: Sensitivity of model predictions to road grade

\begin{tabular}{lllll}
\hline \multirow{2}{*}{ Road grade } & \multicolumn{2}{l}{ Predicted energy consumption } & \multicolumn{2}{l}{ Energy consumption increment } \\
\cline { 2 - 5 } & $k W h / V \cdot m i$ & $k W h / V \cdot k m$ & $k W h / V \cdot m i$ & $k W h / V \cdot k m$ \\
\hline $0 \%$ & 35.83 & 22.25 & 0.00 & 0.00 \\
$1 \%$ & 37.74 & 23.44 & 1.91 & 1.19 \\
$2 \%$ & 40.31 & 25.04 & 4.48 & 2.78 \\
$3 \%$ & 43.65 & 27.11 & 7.82 & 4.86 \\
$4 \%$ & 47.68 & 29.61 & 11.85 & 7.36 \\
\hline
\end{tabular}




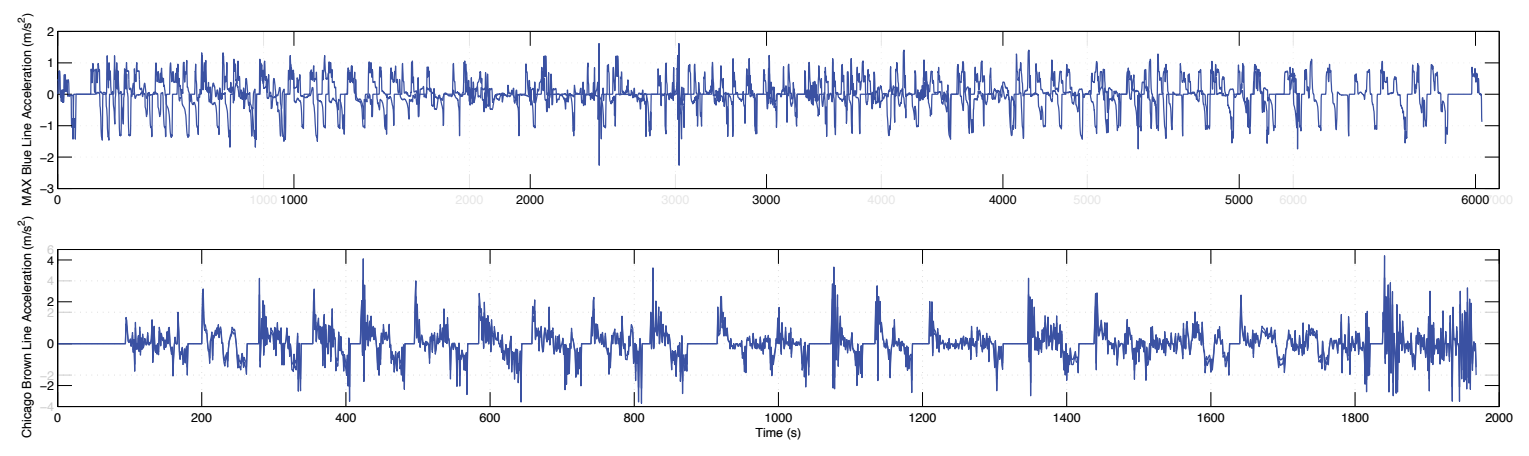

Fig. 7: Instantaneous acceleration levels

Chicago driving cycle is attributed to more aggressive running that produces higher acceleration levels. The model thus can reflect the energy consumption differences between rail lines by accounting for the impact of operational conditions on energy prediction, which is very important for multi-modal transit planning purposes.

Although the model was calibrated against the Portland light rail, it was demonstrated to have good performance for the Chicago heavy rail as well, implying that similar levels of model accuracy could be expected for other transit systems if there is no significant difference in the energy consumption-related system components, such as propulsion technologies, brake systems, train aerodynamics and track infrastructure.

\section{Conclusions}

The paper develops an electric train energy consumption modeling framework considering instantaneous regenerative braking efficiency. The model is calibrated using data from Portland, Oregon utilizing an unconstrained non-linear optimization procedure. The validation effort is conducted using data from Chicago, Illinois by comparing model predictions against NTD estimates, followed by a further discussion on modeling results.

The results demonstrate that regenerative braking efficiency exponentially varies as a function of the deceleration level, rather than an average constant as assumed in previous studies. The model predictions are consistent with the NTD estimates, producing a predicted error of $1.87 \%$ and $-2.31 \%$. Not modeling regenerative braking results in a significant prediction error $(27.39 \%$ and $21.54 \%)$. It is also found that energy recovery reduces the overall power consumption by $20 \%$, significantly improving the system energy efficiency. The results also demonstrate that the proposed modeling approach is able to capture the energy consumption differences associated with train, route and operational characteristics, and thus is applicable for project-level analysis. 
The use of the proposed model does not require any internal engine data given that the power exerted by a train is a function of the vehicle speed and acceleration which can be collected using non-engine instrumentation (e.g. GPS). Accordingly, the model can be easily implemented either in traffic simulation software, smartphone applications or ecotransit programs. The model can thus support GHG emissions prediction and energy and air quality analysis in rail transit.

\section{Limitations and future research}

The major limitation of this study is the limited availability of instantaneous trajectory and energy consumption data. The authors only had access to trajectory data from the Portland and Chicago transit agencies. Consequently, it is recommended that additional data be gathered in the future to test the robustness of the model calibration procedure. More importantly, field energy consumption data is needed to further verify the modeling results.

Another limitation is that the model was only developed for trains from the Portland and Chicago rail systems. Other transit systems may have different traction and brake modes, track infrastructure and propulsion technologies which may lead to different calibration results. Consequently, modeling other electric train modes is an interesting direction to be followed. Also, diesel-electric train modeling is another topic to be investigated as an extension to this study.

Finally, a further study on model application is needed to develop rail transit simulation models, smartphone eco-driving and eco-routing systems and eco-transit programs. These applications will significantly support rail transit energy and air quality analysis.

\section{Acknowledgements}

The authors acknowledge the financial support provided by the TranLIVE University Transportation Center and the Department of Energy ARPA-E Program. In addition, the authors would like to acknowledge the help and data received from Dr. Randall Guensler and his team at Georgia Tech.

\section{References}

[1] U.S. energy information administration (EIA). energy consumption by sector (2014).

[2] Davis SC, Diegel SW, Boundy RG . Transportation energy data book. Oak Ridge National Laboratory, 2015. 
[3] EPA. Inventory of us greenhouse gas emissions and sinks: 1990-2013. Tech. rep.. EPA 430-R-15-004 (2015).

[4] Watanabe S, Koseki T . Energy-saving train scheduling diagram for automatically operated electric railway. Journal of Rail Transport Planning \& Management 5 (3) (2015) 183-193.

[5] González-Gil A , Palacin R , Batty P . Sustainable urban rail systems: Strategies and technologies for optimal management of regenerative braking energy. Energy conversion and management 75 (2013) 374-388.

[6] Feng X . Optimization of target speeds of high-speed railway trains for traction energy saving and transport efficiency improvement. Energy Policy 39 (12) (2011) $7658-7665$.

[7] Feng X, Mao B , Feng X, Feng J . Study on the maximum operation speeds of metro trains for energy saving as well as transport efficiency improvement. Energy 36 (11) (2011) 6577-6582.

[8] Fiori C , Ahn K , Rakha HA . Power-based electric vehicle energy consumption model: Model development and validation. Applied Energy 168 (2016) 257-268.

[9] Gao DW , Mi C , Emadi A . Modeling and simulation of electric and hybrid vehicles. Proceedings of the IEEE 95 (4) (2007) 729-745.

[10] How subway works (2007, http://science.howstuffworks.com/engineering/civil/subway3.htm).

[11] Hay WW . Railroad engineering. Vol. 1. John Wiley \& Sons, 1982.

[12] Gbologah F , Xu Y, Rodgers M, Guensler R . Demonstrating a bottom-up framework for evaluating energy and emissions performance of electric rail transit options. Transportation Research Record: Journal of the Transportation Research Board (2428) (2014) 10-17.

[13] Puchalsky C . Comparison of emissions from light rail transit and bus rapid transit. Transportation Research Record: Journal of the Transportation Research Board (1927) (2005) 31-37.

[14] Messa C . Comparison of emissions from light rail transit, electric commuter rail, and diesel multiple units. Transportation Research Record: Journal of the Transportation Research Board (1955) (2006) 26-33. 
[15] FTA, U.S. department of transportation. National Transit Annual Database,http://www.ntdprogram.gov/ntdprogram/data.htm.

[16] Mittal RK . Energy intensity of intercity passenger rail. final report. Tech. rep.. Department of Transportation, Washington, DC (USA). Office of Univ. Research (1977).

[17] Hopkins JB . Railroads and the environment estimation of fuel consumption in rail transportation, volume 1: Analytical model. Tech. rep.. Federal Railroad Administration. Final Report FRA-OR-D-75-74.I.Washington, DC (1975).

[18] Jong JC , Chang EF . Models for estimating energy consumption of electric trains. Journal of the Eastern Asia Society for Transportation Studies 6 (2005) 278-291.

[19] Barrero R , Tackoen X, Van Mierlo J . Quasi-static simulation method for evaluation of energy consumption in hybrid light rail vehicles. in: 2008 IEEE Vehicle Power and Propulsion Conference. IEEE, 2008. pp. 1-7.

[20] Liu RR , Golovitcher IM . Energy-efficient operation of rail vehicles. Transportation Research Part A: Policy and Practice 37 (10) (2003) 917-932.

[21] Lombardi EJ . Engineering tests performed on the x2000 and ice high speed trainsets. in: Railroad Conference, 1994., Proceedings of the 1994 ASME/IEEE Joint (in Conjunction with Area 1994 Annual Technical Conference). IEEE, 1994. pp. 13-21.

[22] Álvarez A . Energy consumption and emissions of high-speed trains. Transportation Research Record: Journal of the Transportation Research Board (2159) (2010) 2735 .

[23] Kim K , Chien SIJ . Optimal train operation for minimum energy consumption considering track alignment, speed limit, and schedule adherence. Journal of Transportation Engineering 137 (9) (2010) 665-674.

[24] Sicre C , Cucala AP , Fernández A , Lukaszewicz P . Modeling and optimizing energy-efficient manual driving on high-speed lines. IEEJ Transactions on Electrical and Electronic Engineering 7 (6) (2012) 633-640.

[25] Su S , Li X , Tang T, Gao Z . A subway train timetable optimization approach based on energy-efficient operation strategy. IEEE Transactions on Intelligent Transportation Systems 14 (2) (2013) 883-893. 
[26] González-Gil A, Palacin R, Batty P, Powell J . A systems approach to reduce urban rail energy consumption. Energy Conversion and Management 80 (2014) 509-524.

[27] Li X , Lo HK . An energy-efficient scheduling and speed control approach for metro rail operations. Transportation Research Part B: Methodological 64 (2014) 73-89.

[28] Golovitcher IM . Energy efficient control of rail vehicles. in: Systems, Man, and Cybernetics, 2001 IEEE International Conference on. Vol. 1. IEEE, 2001. pp. 658663.

[29] Jenks CW , Goldstein LD, Avery AP, Delaney EP , Lamberton S . National cooperative rail research program (ncrrp) report 3: Comparison of passenger rail energy consumption with competing modes. Tech. rep.. Transportation Research Board, Washington DC (2015).

[30] Argonne national laboratory. autonomie (2015).

[31] Lewis AM , Kelly JC , Keoleian GA . Evaluating the life cycle greenhouse gas emissions from a lightweight plug-in hybrid electric vehicle in a regional context. in: 2012 IEEE International Symposium on Sustainable Systems and Technology (ISSST). IEEE, 2012. pp. 1-6.

[32] Lewis AM , Kelly JC , Keoleian GA . Vehicle lightweighting vs. electrification: Life cycle energy and ghg emissions results for diverse powertrain vehicles. Applied Energy 126 (2014) 13-20.

[33] De Gennaro M, Paffumi E , Scholz H , Martini G . Gis-driven analysis of e-mobility in urban areas: an evaluation of the impact on the electric energy grid. Applied Energy 124 (2014) 94-116.

[34] Rambaldi L, Bocci E , Orecchini F . Preliminary experimental evaluation of a four wheel motors, batteries plus ultracapacitors and series hybrid powertrain. Applied Energy 88 (2) (2011) 442-448.

[35] Abousleiman R , Rawashdeh O . Energy consumption model of an electric vehicle. in: Transportation Electrification Conference and Expo (ITEC), 2015 IEEE. IEEE, 2015. pp. 1-5.

[36] Rajashekara K , Rathore AK . Power conversion and control for fuel cell systems in transportation and stationary power generation. Electric Power Components and Systems 43 (12) (2015) 1376-1387. 
[37] Wang J , Rakha HA . Modeling fuel consumption of hybrid electric buses: Model development and comparison with conventional buses. Transportation Research Record: Journal of the Transportation Research Board (2539) (2016) 94-102.

[38] Association ARE, et al.. Manual for Railway Engineering 1980-1981. American Railway Engineering Association, 1980-1981.

[39] Schmidt EC . Freight Train Resistance: Its Relation to Car Weight. no. 43. The University, 1934.

[40] Tuthill JK . High Speed Freight Train Resistance: Its Relations to Average Car Weight. no. 32. The University, 1948.

[41] Gould G , Niemeier D . Review of regional locomotive emission modeling and the constraints posed by activity data. Transportation Research Record: Journal of the Transportation Research Board (2117) (2009) 24-32.

[42] Volt C . Chevy volt tech watch: regenerative braking (2011).

[43] Pham KD , Thomas RS , Ramirez X . Traction power supply for the portland interstate max light rail extension. in: Transportation Research Circular E-C058: 9 th National Light Rail Transit Conference. 2004. pp. 669-677.

[44] Ceraolo M , Lutzemberger G . Stationary and on-board storage systems to enhance energy and cost efficiency of tramways. Journal of Power Sources 264 (2014) 128139.

[45] Frilli A, Meli E, Nocciolini D , Pugi L, Rindi A . Energetic optimization of regenerative braking for high speed railway systems. Energy Conversion and Management 129 (2016) 200-215.

[46] International union of railways. regenerative braking for $50 \mathrm{hz}, 25 \mathrm{kv}$ systems (2002, http://www.railway-energy.org/tfee/index.php).

[47] Sudhir, M.D., braking green for mumbai trains (2012, http://blog.siemens.co.in/?p=4559).

[48] Bombardier. Bombardier environmental technologies help delhi metro achieve world-first under united nations-backed climate change initiative (http://csr.bombardier.com/en/media-center/ csr-news/25-bombardiersenvironmental-technologies-help-delhimetro-achieve-world-first-under-unitednations-backed climate changeinitiative. Accessed July 26, 2013.). 
Appendix A. Model Parameter Annotation 
Table A1: Description of model parameters

\begin{tabular}{|c|c|c|}
\hline Name & Description & Unit \\
\hline$E$ & Annual energy consumption & $k W h$ \\
\hline$E_{p}$ & Annual energy consumed per passenger kilometer & $k W h / P \cdot k m$ \\
\hline$E_{s}$ & Annual energy consumed per seating kilometer & $k W h / S \cdot k m$ \\
\hline$E_{v}$ & Annual energy consumed per vehicle kilometer & $k W h / V \cdot k m$ \\
\hline$M_{p}$ & Annual passenger kilometer & $P \cdot k m$ \\
\hline$M_{s}$ & Annual seating kilometer & $S \cdot k m$ \\
\hline$M_{v}$ & Annual vehicle kilometer & $V \cdot k m$ \\
\hline$C$ & Train capacity & - \\
\hline$\beta$ & Line loss factor & - \\
\hline$E C(t)$ & Instantaneous energy consumption & $k W$ \\
\hline$E C_{r e}(t)$ & Instantaneous energy regeneration & $k W$ \\
\hline$P(t)$ & Instantaneous tractive power & $k W$ \\
\hline$\alpha_{01}$ & Head-end power (HEP) & $k W$ \\
\hline$\alpha_{02}$ & Fraction of HEP (0.05 is suggested by [12]) & $k W$ \\
\hline$\beta_{01}, \beta_{02}$ & Dummy variable & - \\
\hline$\eta_{\text {re }}$ & Instantaneous regenerative efficiency & - \\
\hline$E C_{d}$ & Trip energy consumption per unit distance & $k W h / V \cdot k m$ \\
\hline$F(t)$ & Instantaneous tractive force & $N$ \\
\hline$u(t)$ & Instantaneous speed & $\mathrm{km} / \mathrm{h}$ \\
\hline$w_{p}$ & Weight per railcar axle & ton \\
\hline$n_{p}$ & Number of axles per railcar & - \\
\hline$K$ & Train drag coefficient (0.07 suggested by [11]) & - \\
\hline$\theta$ & Road grade & $\%$ \\
\hline$L$ & Distance a train moved in one second & $m$ \\
\hline$M$ & Total train weight & ton \\
\hline$\alpha$ & Regenerative efficiency model parameter & - \\
\hline$a(t)$ & Instantaneous deceleration level & $\mathrm{m} / \mathrm{s}^{2}$ \\
\hline$d$ & distance covered by the entire driving cycle & $\mathrm{km}$ \\
\hline$E C_{N T D}$ & NTD energy rate & $k W h / V \cdot k m$ \\
\hline
\end{tabular}




\section{Appendix B. Track information}

Table B1: Track information for the MAX Blue Line

\begin{tabular}{|c|c|c|c|c|c|}
\hline \multirow[b]{2}{*}{ Station Name } & \multicolumn{2}{|c|}{ Milepost } & \multicolumn{2}{|c|}{ Elevation } & \multirow[b]{2}{*}{ Grade to Next Station } \\
\hline & mile & kilometer & foot & meter & \\
\hline Hatfield Government Center Station & 0.000 & 0.000 & 200.000 & 60.960 & 0.00049 \\
\hline Hillsboro Central /SE 3rd TC & 0.360 & 0.579 & 200.940 & 61.247 & -0.00122 \\
\hline Tuality Hospital/SE 8th & 0.701 & 1.128 & 198.745 & 60.577 & -0.00580 \\
\hline Washington/SE 12th & 1.117 & 1.799 & 185.995 & 56.691 & 0.00320 \\
\hline Fair Complex/Hillsboro Airport & 2.348 & 3.781 & 206.789 & 63.029 & -0.00079 \\
\hline Hawthorn Farm & 3.116 & 5.016 & 203.609 & 62.060 & 0.00310 \\
\hline Orenco/NW 231st & 3.845 & 6.190 & 215.559 & 65.702 & -0.00095 \\
\hline Quatama/NW 205th & 5.265 & 8.477 & 208.439 & 63.532 & 0.00095 \\
\hline Willow Creek/SW 185th & 6.250 & 10.063 & 213.379 & 65.038 & 0.00047 \\
\hline Elmonica/SW 170th & 7.273 & 11.709 & 215.894 & 65.804 & 0.00210 \\
\hline Merlo/SW 158th & 7.860 & 12.654 & 222.419 & 67.793 & 0.00037 \\
\hline Beaverton Creek & 8.409 & 13.539 & 223.499 & 68.122 & -0.00532 \\
\hline Millikan Way & 9.110 & 14.667 & 203.829 & 62.127 & 0.00122 \\
\hline Beaverton Central & 9.848 & 15.856 & 208.594 & 63.579 & -0.00124 \\
\hline Beaverton TC & 10.170 & 16.374 & 206.494 & 62.939 & 0.02039 \\
\hline Sunset TC & 12.197 & 19.637 & 424.711 & 129.452 & 0.00325 \\
\hline Washington Park & 15.426 & 24.836 & 480.081 & 146.329 & -0.04455 \\
\hline Goose Hollow/SW Jefferson & 16.818 & 27.077 & 152.648 & 46.527 & -0.01191 \\
\hline Kings Hill/SW Salmon & 17.045 & 27.443 & 138.358 & 42.171 & 0.00804 \\
\hline JELD-WEN Field & 17.159 & 27.626 & 143.183 & 43.642 & 0.00690 \\
\hline 13 th st & 17.424 & 28.053 & 152.838 & 46.585 & -0.02200 \\
\hline Galleria/SW 10th & 17.557 & 28.266 & 137.438 & 41.891 & -0.02200 \\
\hline Pioneer Square North & 17.727 & 28.541 & 117.638 & 35.856 & -0.02200 \\
\hline Mall/SW 5th & 17.841 & 28.724 & 104.438 & 31.833 & -0.01100 \\
\hline SW 3rd & 18.030 & 29.029 & 93.438 & 28.480 & -0.00895 \\
\hline Oak/SW 1st & 18.220 & 29.334 & 84.488 & 25.752 & -0.00117 \\
\hline Skidmore Fountain & 18.447 & 29.700 & 83.088 & 25.325 & 0.00334 \\
\hline Old Town/Chinatown & 18.574 & 29.904 & 85.328 & 26.008 & 0.03266 \\
\hline Rose Quarter TC & 19.085 & 30.727 & 173.498 & 52.882 & 0.04261 \\
\hline Convention Center & 19.218 & 30.941 & 203.328 & 61.974 & 0.01174 \\
\hline NE 7th & 19.545 & 31.468 & 223.638 & 68.165 & 0.00500 \\
\hline Lloyd Center/NE 11th & 19.634 & 31.611 & 225.988 & 68.881 & 0.00051 \\
\hline
\end{tabular}


Hollywood/NE 42nd TC

NE 60th

NE 82nd

Gateway/NE 99th TC

E 102nd

E 122nd

E 148th

E 162nd

E 172nd

E 181st

Rockwood/E 188th

Ruby Junction/E 197th

Gresham City Hall

Gresham Central TC

Cleveland

$\begin{array}{lllll}21.377 & 34.417 & 230.673 & 70.309 & 0.00681 \\ 22.381 & 36.033 & 266.773 & 81.312 & 0.00398 \\ 23.782 & 38.289 & 296.213 & 90.286 & 0.02047 \\ 24.559 & 39.540 & 380.133 & 115.864 & -0.01174 \\ 25.402 & 40.896 & 327.873 & 99.936 & 0.00250 \\ 26.585 & 42.802 & 343.468 & 104.689 & 0.00331 \\ 27.708 & 44.610 & 363.068 & 110.663 & -0.00660 \\ 28.371 & 45.678 & 339.968 & 103.622 & -0.00808 \\ 28.864 & 46.470 & 318.968 & 97.221 & -0.00552 \\ 29.299 & 47.172 & 306.268 & 93.350 & 0.00275 \\ 29.678 & 47.782 & 311.768 & 95.027 & 0.00584 \\ 30.227 & 48.666 & 328.718 & 100.193 & 0.00866 \\ 31.610 & 50.892 & 391.918 & 119.456 & 0.01529 \\ 32.121 & 51.715 & 433.198 & 132.039 & 0.01419 \\ 32.538 & 52.386 & 464.408 & 141.551 & 0.01419\end{array}$


Table B2: Track information for the Chicago Brown Line

\begin{tabular}{|c|c|c|c|c|c|}
\hline \multirow[b]{2}{*}{ Station Name } & \multicolumn{2}{|c|}{ Milepost } & \multicolumn{2}{|c|}{ Elevation } & \multirow[b]{2}{*}{ Grade to Next Station } \\
\hline & mile & kilometer & foot & meter & \\
\hline Kimball & 0.000 & 0.000 & 548.314 & 167.126 & -0.0255 \\
\hline Kedzie & 0.252 & 0.406 & 514.337 & 156.770 & -0.0169 \\
\hline Francisco & 0.626 & 1.008 & 481.030 & 146.618 & -0.0011 \\
\hline Rockwell & 0.983 & 1.583 & 479.016 & 146.004 & 0.0094 \\
\hline Western & 1.322 & 2.128 & 495.863 & 151.139 & 0.0025 \\
\hline Damen & 1.766 & 2.844 & 501.795 & 152.947 & 0.0106 \\
\hline Montrose & 2.245 & 3.614 & 528.681 & 161.142 & 0.0196 \\
\hline Irving Park & 2.747 & 4.423 & 580.702 & 176.998 & -0.0223 \\
\hline Addison & 3.222 & 5.187 & 524.777 & 159.952 & 0.0072 \\
\hline Paulina & 3.592 & 5.784 & 538.858 & 164.244 & 0.0067 \\
\hline Southport & 3.955 & 6.368 & 551.759 & 168.176 & -0.0030 \\
\hline Belmont & 4.692 & 7.554 & 539.964 & 164.581 & 0.0125 \\
\hline Wellington & 4.897 & 7.885 & 553.511 & 168.710 & -0.0052 \\
\hline Diversey & 5.155 & 8.300 & 546.453 & 166.559 & -0.0187 \\
\hline Fullerton & 5.642 & 9.084 & 498.304 & 151.883 & -0.0071 \\
\hline Armitage & 6.106 & 9.831 & 480.804 & 146.549 & 0.0237 \\
\hline Sedgwick & 7.180 & 11.560 & 615.272 & 187.535 & -0.0110 \\
\hline Chicago & 8.230 & 13.250 & 554.058 & 168.877 & 0.0091 \\
\hline Merchandise Mart & 8.711 & 14.024 & 577.077 & 175.893 & 0.0091 \\
\hline
\end{tabular}

